\title{
Observation of Tumour-induced Reorganization in Structural and Functional Architecture of the Brain in Three Pre-surgical Patients with Left Frontal-temporal Brain Tumour: A Combination of MEG, DTI and Neuropsychological Assessment (Pemerhatian Tumor Menyebabkan Perubahan pada Struktur dan Fungsi Otak dalam Tiga Pesakit Pra-pembedahan yang menghidap Tumor Otak pada Bahagian Frontal-Temporal: Kombinasi MEG, DTI dan Penilaian Neuropsikologi)
}

HANANI ABDUL MANAN*, ZAMZURI IDRIS, MOHAMMED FARUQUE REZA, WAN NOR AZLEN WAN MOHAMAD \& JAFRI MALIN ABDULLAH

\section{ABSTRACT}

Visual function is mainly located within the bilateral hemisphere of the occipital lobes of the brain. However, our functional magnetoencephalography (MEG) result has demonstrated the reorganization of brain activity in the occipital area in patients with left-sided brain tumour. The results showed that brain laterality changes from bilateral to unilateral activation of the occipital area. Right occipital area (contralateral areas to the tumour), shows increase intensity of activation. Diffusion tensor imaging (DTI) with fibre tracking was performed to further investigate this brain laterality modification and the findings confirmed there is an alteration in the left hemisphere fibre optic tracts. This functional modification and changes of the brain laterality and optic tracts in the brain is suspected to be the result of tumour growth induced changes. The present observation will be discussed in term of the mechanism of tumour induced reorganization and changes with the corroborating evidence from MEG, DTI and neuropsychological assessment.

Keywords: Diffusion tensor imaging; magnetoencephalography; neuroplasticity; visual evoked field and functional shifted

\section{ABSTRAK}

Fungsi visual terletak pada kedua-dua belah bahagian hemisfera lobus osipital. Walau bagaimanapun, hasil kajian kefungsian dengan menggunakan magnetoensefalografi (MEG) menunjukkan berlakunya pengubahsuaian pada pengaktifan otak bagi pesakit yang menghidap tumor pada sebelah kiri otak. Keputusan menunjukkan pengaktifan unilateral pada pesakit tersebut iaitu pada sebelah kontralateral pada bahagian tumor. Keputusan kajian ini turut disokong oleh keputusan daripada pengimejan tensor resapan (DTI). Keputusan daripada pengimejan DTI turut menunjukkan terdapatnya perubahan pada optik fiber pada sebelah kiri hemisfera. Perubahan kefungsian dan perubahan pada optik fiber ini dicadangkan disebabkan oleh tumor. Keputusan pemerhatian ini akan dibincangkan daripada segi makanisme keplastikan neuro dengan menghubungkan bukti daripada pengimejan MEG, DTI dan ujian psikologi.

Kata kunci: Keplastikan neuro; magnetoensefalografi; pengimejan tensor resapan; rangsangan medan penglihatan dan kefungsian teranjak

\section{INTRODUCTION}

The visual system is unique as much of visual processing occurs outside the brain within the retina of the eye. In normal condition, both hemispheres of the brain are working together interconnected via corpus callosum and commissures (Manan et al. 2015). Integration of information from each side appears to be crucial for normal functional activities. However, there are cases such as in brain tumour where one or both sides of the brain are damaged making them unable to function normally (Boissonneau \& Duffau 2017). Studies of human lesions have shown that bilateral lesions can produce catastrophic behaviour impairment, whereas, unilateral lesions often produce little or no effect (Maeshima et al. 1992; Wilkinson et al.2009). Lesions can lead to reorganization of networks responsible for visual processing, in which is compensating the brain lesion (Sabbah et al. 2017). Appreciative the natural history of tumour is essential in order to have a better understanding in the network reorganization and changes of the functional areas due to the tumour growth (Duffau 2014). This includes the potential for invasion, the ability to progress and the behaviour of the surrounding functional area. Different types of tumour will behave differently and the functional reorganization in response to these tumours would also be different (Reichert et al. 2017). For example, low grade glioma (LGG) such as pilocytic astrocytoma (PA), shows a continuous constant growth, with a mean tumour diameter growing on average about $4 \mathrm{~mm}$ per year (Krieg et al. 2103). LGG invades the main white-matter pathway within the lesional hemisphere 
and spread contralaterally via the corpus callosum (Walker \& Kaye 2003). Recent study showed that the progression of LGG triggers a large functional reorganization within cerebral structures (Duffau 2014). This brain plasticity may allow a functional compensation (Roux et al. 2000), therefore other functional brain area will take over the processing center.

Brain plasticity is a continuous process and allowing remodelling of neurosynaptic maps. The purpose of this mechanism is to optimise the functioning of brain networks (Bashir et al. 2010; Bavelier \& Neville 2002). Hypotheses have been proposed to elucidate the pathophysiological fundamental mechanism of neural plasticity. At a synapse level, the efficiency of synaptic transmission is adaptively modulated based on the historic pattern of synaptic activity (Di et al. 2016). The synaptic weight of individual neurons is homeostatically regulated by compensatory mechanisms to keep cellular excitability at stable levels (Di et al. 2016). Such synaptic plasticity serves to maintain the excitation-inhabitation balance within a neural network and provides essential mechanisms underlying higher cognitive functions including learning and memory (Reichert et al. 2107). At the network level, neuroplasticity is critically involved in functional recovery from brain damage or loss of sensory information (Park et al.2017). Neuroplasticity has a critical role during learning and recovery from lesions in the peripheral nervous system and CNS. The behavioural consequence of this mechanism has been investigated recently in human (Bashir et al. 2010; Begley \& Check 2000). However, the observation of neuroplasticity and the pattern of brain reorganization and changes involved in the patients with brain tumour and the effects to the surrounding functional areas have not been documented using combination of neuroimaging techniques such as magnetoencephalography (MEG) and diffusion tensor imaging (DTI). DTI is a magnetic resonance imaging (MRI) technique that can be used to characterize the directional properties of the diffusion of water molecules (Dellani et al.2007). Application of this technique to the human brain can provide unique in vivo visualization of white matter architecture and its structural connectivity (Oberlin et al. 2015). Since DTI offers the only non-invasive method of demonstrating white matter tracts in vivo, it may be useful for identifying the fibres tracts non-invasively.

Pattern-reversal visual evoked fields (PR-VEF) are useful for investigating the physiology and pathophysiology of the visual system, including visual pathways and the visual cortex. Furthermore, the PR-VEF is a well-recognised and useful diagnostic tool to assess human visual function for neurological disorders (Mizuno et al. 2013; Roux et al. 2000). MEG has several advantages in localizing cortical sources (Shahani et al. 2001). Several MEG studies analysing PR-VEF have been reported (Nakamura et al. 2015; Seki et al.2010), but the different between previous study and current study is this is an observational study to evaluate the differences of the source localization during PR-VEF on patients with different types and location of brain tumour but associated to a similar impairment.
The purpose of the present study was to observe and report the reorganization and changes that has been made by the brain in response to the tumour. The present study recorded both MEG and DTI from patients with left hemisphere brain tumour. The observation of the tumour induced plasticity and changes will be discussed based on the MEG, DTI and neuropsychological assessments.

\section{MATERIALS AND METHODS}

\section{PARTICIPANTS}

Three male participants (mean age 34.67 years, $\mathrm{SD}=21.39$ ) with left frontal temporal brain tumour and one male control participant (35 years old) were recruited. All were reported of no history and no current use of psychoactive medications. Demographic data and details of the patients are in Table 1 . The health status of participants was examined through an interview prior to the experiment. After full explanation of the nature and risks of the study, informed consent was obtained according to the protocol approved by the Institutional Ethics Committee (IEC) of Universiti Sains Malaysia.

\section{TASK DESIGN}

Magnetoencephalography (MEG) data were recorded continuously during the performance of a square checkerboard pattern. Figure 1(A) depicts a sequence of checkerboard used during the study. The stimulus is presented continuously for about $7 \mathrm{~min}$. The stimulus was presented visually on a computer monitor at eye level, approximately $60 \mathrm{~cm}$ in front of the patient's nose. Stimuli consisted of flickering (reversing) checkerboard patterns on a homogenous white background: check size of $2^{\circ}, 50^{\circ}$ orientation, $8^{\circ}$ from a fixation point (a small red cross at the center of the screen) along the downward diagonal in left or right lower visual quadrant. The stimulus used, the participants set up and MEG apparatus is shown in Figure 1(B) and 1(C).

\section{MAGNETOENCEPHALOGRAPHY AND DATA PROCESSING}

MEG data were collected using a 306-channel Vectorview system (ElektaNeuromag, Helsinki) in a light ElektaNeuromag magnetically-shielded room. A magnetometer and two orthogonal planar gradiometers were located at each of 102 positions. Vertical and horizontal eye movements were recorded using paired EOG electrodes. Four head position indicator (HPI) coils were used to monitor the head position. A3D digitizer (FastrakPolhemus Inc., Colchester, VA) was used to record the threedimensional locations of the HPI coils and approximately 200 'head points' across the scalp and three anatomical fiducials (the nasion and left and right pre-auricular points). Data were sampled $1000 \mathrm{~Hz}$ and pre-processed using MaxFilter software with movement compensation. Software Brain Electrical Source Analysis (BESA version 
TABLE 1. Demographic data and patient details obtained from 3 participants

\begin{tabular}{|c|c|c|c|c|}
\hline Participants & Age & Area of the tumour & Tumour size & Diagnosis \\
\hline 1 & 46 & frontal lobe & $\begin{array}{l}\text { maximum diameter } \\
6.0 \mathrm{~cm}\end{array}$ & $\begin{array}{l}\text { convexity } \\
\text { meningioma }\end{array}$ \\
\hline 2 & 48 & $\begin{array}{l}\text { frontal-temporal lobe } \\
\text { resulting in midline shift of } 0.5 \mathrm{~cm} \text { to the } \\
\text { contralateral brain }\end{array}$ & $\begin{array}{l}\text { maximum diameter } \\
9.0 \mathrm{~cm}\end{array}$ & $\begin{array}{l}\text { convexity } \\
\text { meningioma }\end{array}$ \\
\hline 3 & 10 & $\begin{array}{l}\text { temporal-parietal lobe } \\
\text { temporal lobe extending up till the parietal } \\
\text { lobe resulting in midline shift of } 1.5 \mathrm{~cm} \text { to the } \\
\text { contralateral }\end{array}$ & $\begin{array}{l}\text { a large solid-cystic } \\
\text { tumour measuring } \\
8.4 \times 6.5 \times 5.3 \mathrm{~cm}\end{array}$ & $\begin{array}{c}\text { pilocytic } \\
\text { astrocytoma }\end{array}$ \\
\hline
\end{tabular}
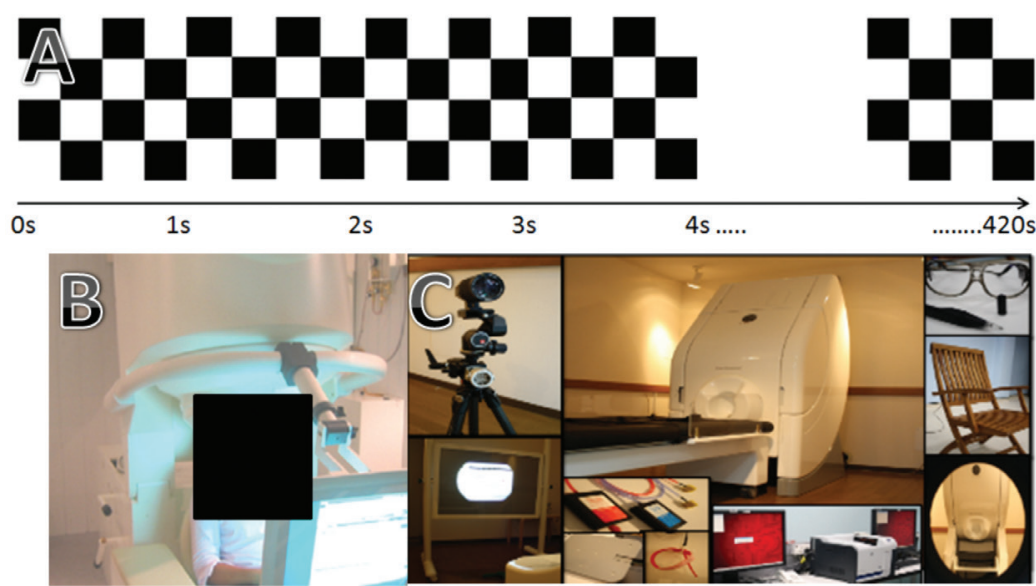

FIGURE 1. (A) shows sequence of checkerboard, pattern-reversal visual evoked fields (PR-VEF) used during the study. The stimulus is presented continuously for about $7 \mathrm{~min}$. Participant need to focus to the stimulus presented, not daydreaming, stay awake and must not fall asleep during the scan, (B) shows how patients were positioned in the MEG scanner, stimulus was presented in the screen as in the picture. The screen will be position in front of the participant and $(\mathrm{C})$ depicted the MEG's room, apparatus need to be used with MEG and how participant is position during the study

$6.0, \mathrm{GmbH}$, Graefelfing, Germany) was used to process for source analysis of the waveforms of the visual processing area. An MRI image was also collected using 3-tesla magnetic resonance imaging (MRI) (Philips Achieva 3.0T $\mathrm{X}$-series, Philips, Netherlands).

MEG SOURCE ANALYSIS

SOURCE ANALYSIS AND VISUAL EVOKED FIELD (VEF)

In order to provide the precise spatial localizations compared to distributed source models, for example minimum norm approaches, equivalent current dipole approach was used. For the starting point of the dipoles, in order to maximize the explained spatial variance of the scalp-recorded potentials using maximization algorithm (EM), the algorithm iteratively shift dipole sources at the at specific brain location with a specific dipole orientation. The source dipole solutions for the N100 component were determined.

Data were filtered using high pass filter $(>1 \mathrm{~Hz}$, Butterworth filter $6 \mathrm{~dB} /$ oct with no added padding) and the artefact rejection threshold was set to $2500 \mathrm{fT}$ for magnetometers and $900 \mathrm{fT}$ for gradiometers. Using adaptive artefact correction, eye-blinks were corrected and modelled in the source analysis with one fixed source. Epochs were low pass filtered to $200 \mathrm{~Hz}$ (Butterworth filter $24 \mathrm{~dB} / \mathrm{oct}$ ), time locked to the tone onset, baseline corrected (-50 to $200 \mathrm{~ms}$ ). Source analysis of evoked responses from the gradiometer MEG channels, was performed on the visual processing response. The forward model topography (leadfield) was estimated using a realistic head model, coregistered by fiducial and digitised scalp loci. The inverse of this leadfield matrix was applied to the gradiometer data to estimate the source waveforms, varying source location and orientation iteratively until the residual difference between scalp and model waveforms was minimized. The data were fitted to two bilateral equivalent current dipoles (regional sources). The fits were constrained by imposing symmetry on the two sources, but not constrained by location or orientation and with regularisation constant $1 \%$ to stabilise source fitting in the presence of noise. 
For the N100 (50 - $150 \mathrm{~ms})$ produced in a two source solution that was most likely fundamental the generation of scalp recorded potential in these time windows. Two source dipoles were fitted distinctly with the constraint of having symmetrical sources in each hemisphere. Using different starting locations, these symmetric dipoles were allocated consistently to the inferior occipito-temporal cortex for the N100. Dipoles were fit sequentially in the following order: first, a single dipole (No. 1) was placed on the right occipital activation and fit over $50-150 \mathrm{~ms}$. Second, the contralateral dipole in pair No 2 was placed on the left occipital activation and the pair was fit over $50-150 \mathrm{~ms}$.

\section{DIFFUSSION TENSOR IMAGING DTI}

DTI data were acquired using the FiberTrak package included in the Extended MRI Workspace (EWS) R 2.6.3. The DTI data were transferred to a workstation (8 GB RAM, $2.33 \mathrm{GHz}$ Intel Xeon, Windows 64 bit). This fibre tracking software is based on the fibre assignment by continuous tracking (FACT) algorithm (Mori \& van Zijl 2002). To minimize artefacts caused by movement and eddy currents, co-registration to $b=0$ images was performed using the diffusion registration package in the EWS. Fractional anisotropy maps were generated in the EWS. Settings for the tractography were as the following: FA $>0.25$, $\max$ angle change $90^{\circ}$ and min fibre length $30 \mathrm{~mm}$.

\section{NEUROPSYCHOLOGY TEST}

Visual-based neuropsychological examination used in the present study including: Benton Visual Retention Test (BVRT). BVRT measures visual perception and visual memory and BVRT can also be used to help identify possible learning disabilities among other afflictions that might affect participants' memory. The individual examined is shown 10 designs, one at a time and asked to reproduce each one as exactly as possible on plain paper from memory. The test is untimed and the results are professionally scored by form, shape, pattern and arrangement on the paper; Visual based stimulus Wechsler memory scale (WMS) - abbreviated, performance IQ (visual-based stimulus). WMS is a neuropsychological test designed to measure different memory functions in a person. WMS is made up of seven subtests: Spatial addition, symbol span, design memory, general cognitive screener, logical memory (I \& II), verbal paired associates (I \& II) and visual reproduction (I \& II). A participant's performance is reported as five Index Scores: Auditory memory, visual memory, visual working memory, immediate memory and delayed memory; Wechsler abbreviated scale of intelligence (WASI). WASI is a general intelligence or IQ test designed to assess specific and overall cognitive capabilities and is individually administered to children, adolescents and adults (ages 6-89).

\section{DATA ANALYSIS (MEG, DTI AND \\ NEUROPSYCHOLOGICAL ASSESSMENT)}

For MEG source analysis, BESA software was used to analyse the data. Among all 3D sources imaging analysis, LORETA yields the best fit for the present data. Therefore, LORETA analysis was used to analyse all the data. DTI data was analysed using package included in the extended MRI workspace (EWS) R 2.6.3. The DTI fibre tracking software is based on the fibre assignment by continuous tracking (FACT) algorithm. Finally, neuropsychological assessment such as BVRT, WMS and WASI was used in the present study. The results of the tests were assessed and scored by the psychologist. The results were referred to the psychologist's manual. The score of the participants were tabulated in Table 2.

\section{RESULTS}

\section{NEUROPSYCHOLOGY ASSESSMENT}

Table 2 tabulated the participant's performance during neuropsychological test. BVRT result showed that participants' performances were not within the expected range and below average. The second neuropsychological task WMS, also showed the same result, participant's performance was below average. Finally, for WASI one participant scored below average and the other two received average score.

DTI

Figure 2(A) depicts MRI-BESA image in the coronal view of patient 1 . Tractogram of the optic tract fibres in

TABLE 2. Performance data of neuropsychology test

\begin{tabular}{cccc}
\hline Patients & \multicolumn{2}{c}{ Score } & \\
\cline { 2 - 4 } & $\begin{array}{c}\text { Benton visual retention test } \\
\text { (BVRT) }\end{array}$ & $\begin{array}{c}\text { Visual based stimulus } \\
\text { Wechsler memory scale (WMS) } \\
\text { abbreviated }\end{array}$ & $\begin{array}{c}\text { Performance IQ } \\
\text { (visual based stimulus) } \\
\text { Wechsler abbreviated scale of } \\
\text { intelligence (WASI) }\end{array}$ \\
\hline 1 & 2 (not within the expected range) & 1 (extremely low range) & 80 (low average) \\
2 & 5 (not within the expected range) & 2 (extremely low range) & 91 (average) \\
3 & 5 (not within the expected range) & 1 (extremely low range) & 93 (average) \\
4 & 10 (Within the normal range) & 9 (Within the normal range) & 120 \\
(control participant) & & & (Within the normal range) \\
\hline
\end{tabular}


axial, coronal and sagittal plane is represented in Figure 2(B) and 2(C). The optic pathway fibres are in green indicating structural connectivity. The white matter tracts were visually inspected. Comparing between the two hemispheres, right hemisphere fibres optic tracts were more apparent as in Figure 2(B) and 2(C) (optic tracts and radiations are in green and asterisk).

An axial MRI image for patient 2 is tabulated in Figure 3 (A). The results of tractogram from patient 2 also share a similar pattern of geographical map, as in Figure 3(B) and $3(\mathrm{C})$. Both tractograms show the intensity of the optic tract fibre to be more pronounced in the contralateral area to the tumour. The results indicated more massive connections in the contralateral area to the tumour.
MEG

Figure 4(A) shows the MRI-BESA image in the coronal view of patient 3. The results indicated some atypical features of source localization and brain activity of the visual evoked field (VEF) MEG, as in Figure 4(B) and 4(C). Unexpectedly; unilateral hemisphere of right occipital area was activated even though the stimulus was presented to both eyes. Source localization also shows a similar pattern of result, an intense localization in the contralateral area to the tumour.

A VEF-MEG result of patient 3 is also supported with VEF-MEG's of patients 1 and 2, which demonstrate a similar pattern of source localization and brain activity. The results indicated only one hemisphere (right hemisphere) of the

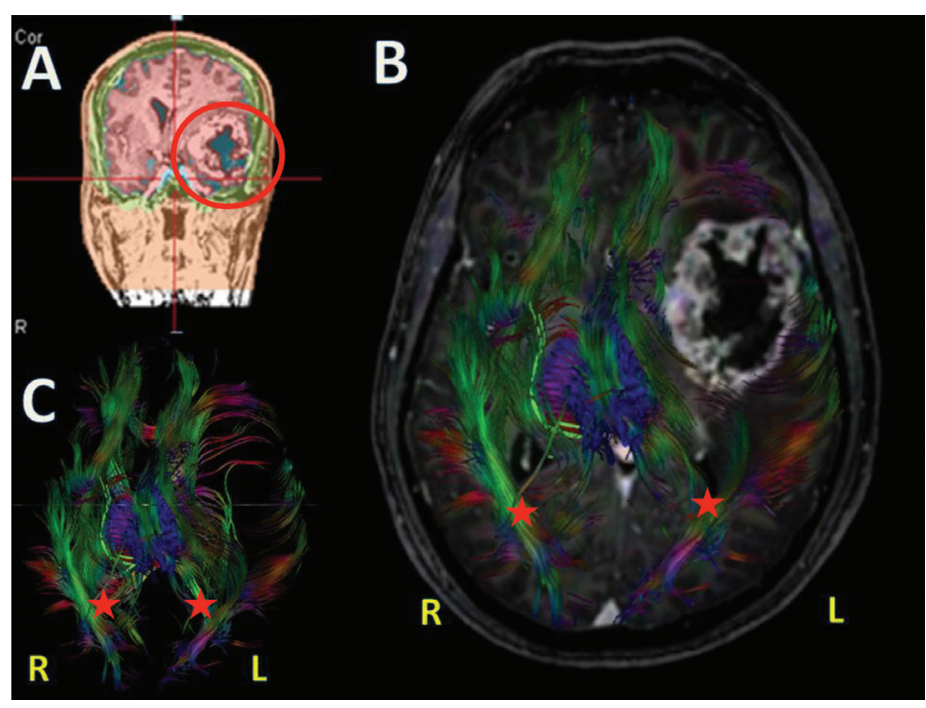

FIGURE 2. (A) BESA brain images in coronal an showing convexity meningioma on the left frontal temporal lobe (in the red circle), (B) axial view of the optic tracts and radiations (green and asterisk), (C) axial view of the optic tracts (green) without MRI brain template and (D) sagittal view of the tractogram from the contralateral of the tumour. L: Left, R: Right, P: Posterior

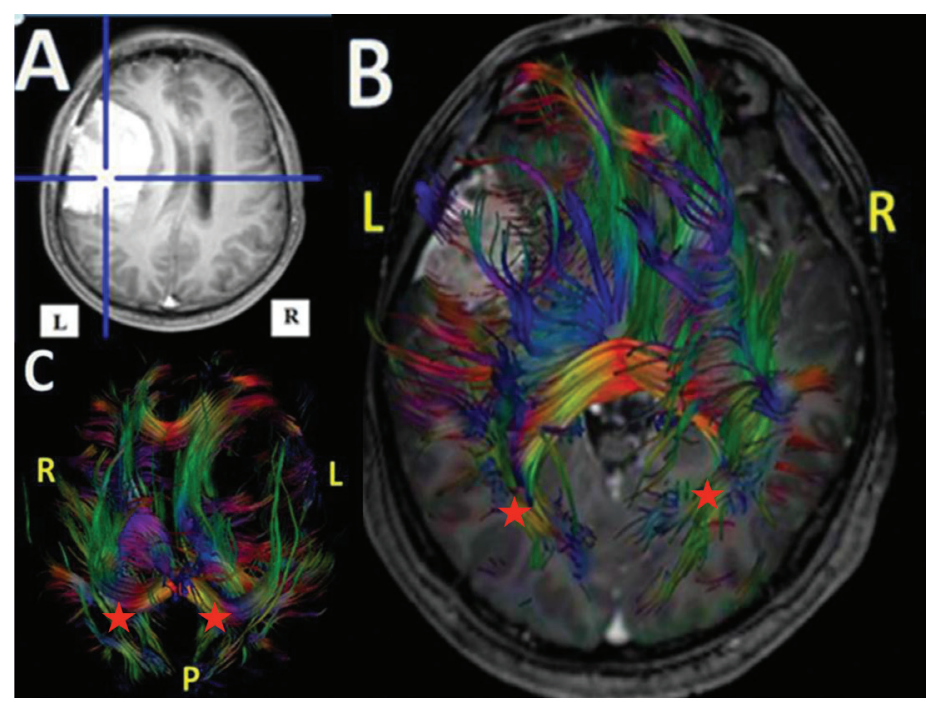

FIGURE 3. (A) Axial MRI brain image showing convexity meningioma near the left frontal lobe, (B) axial tractogram superimposed on T1 image and (C) axial tractogram without MRI brain template showing the visual pathway fibers. The fibers related to vision are in green (green and asterisk). L: Left, R: Right, P: Posterior 

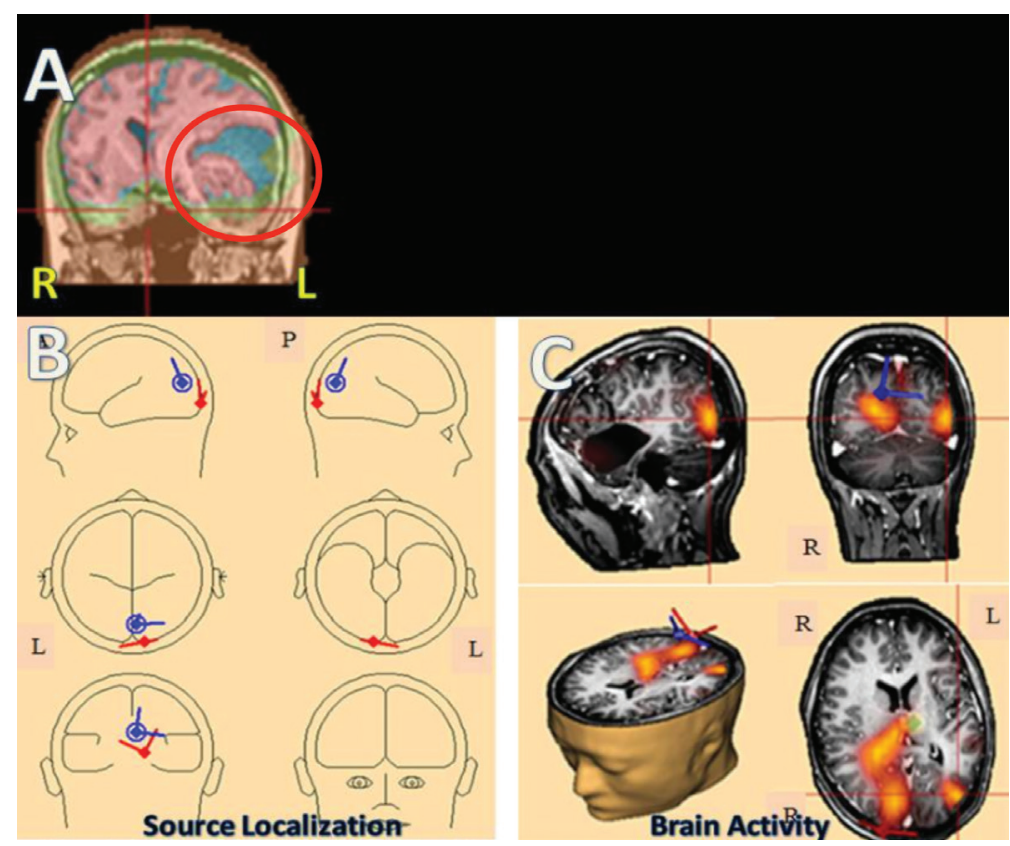

FIGURE 4. (A) BESA brain images coronal depicting a solid-cystic tumour at the left temporo-parietal region (tumour is in the red circle), (B) source localization and (C) brain activity of patient 3 were matched. The results showed activation of the unilateral occipital area during visual evoked fields. Brain activation shows stronger activation on the right hemisphere. L: Left, R: Right, P: Posterior

brain was activated but with intense brain signal, the activation area is contralateral to the tumour. The present study proposed that both source localization and brain activity of the tumour area were shifted to the contralateral area to the tumour in response to the tumour growth. As a comparison, Figure 5 shows visual activation and source localization of a control participant. The result as expected, a bilateral activation of the visual processing area.

\section{DISCUSSION}

In this study, we discuss one control participant and three patients with different type of brain tumours; convexity meningioma and pilocytic astrocytoma (PA) in the left hemisphere. The results demonstrate atypical pattern of brain activity with identical visual evoked fields (VEF) localization in all three patients. We discuss the contribution of a relatively new functional mapping technique using MEG and DTI to our understanding of brain reorganization in response to progressive growth brain tumour. Finally, we consider the clinical implications of interactions between tumour progression and brain plasticity.

\section{NEUROPSYCHOLOGICAL TEST IN RELATION TO MEG AND DTI}

In comparison to the behavioural performance of the control participant, the performances of patients in the all three tasks are below average. The BVRT and WMS result showed that participants' performances were not within the expected range and below average. Furthermore, WASI scored also showed low average for patient 1 . These neuropsychological results are congruent with patients' complaint that they have difficulties and have a low ability to recall, remembering and have problems with reading. These results suggested that there is association with the structural and functional alteration of the brain in response to the tumour growth. The present result also supported the MEG and DTI which demonstrated atypical source localization and brain activity which is unilateral activation on the right occipital area. There was no activation in the left hemisphere, ipsilateral to the tumour. Therefore, both neuropsychological and neuroimaging result are in agreement to one another.

\section{BRAIN CHANGES IN RELATION TO THE INSULT}

Compared to the control participant with activation of bilateral hemisphere of the occipital area during VEF (Figures 6(A) and 4(B)), all three patients demonstrated atypical source localization and brain activity. The results of the three patients demonstrated unilateral activation on the right occipital area. There was very little activation in the left hemisphere, ipsilateral to the tumour. This result proposed a reorganization of the main functional area in the bilateral to unilateral occipital due to the tumour invasion. The present study suggests that this behaviour of localization modification was due to the tumour suppression of the optic nerve and main functional area of the visual processing. Therefore, contralateral area of the functional lesion-visual would take place in response to the brain insult, with increased contralateral and reduced ipsilateral activity. Similar pattern of brain behaviour was also found in a previous study where a series of 


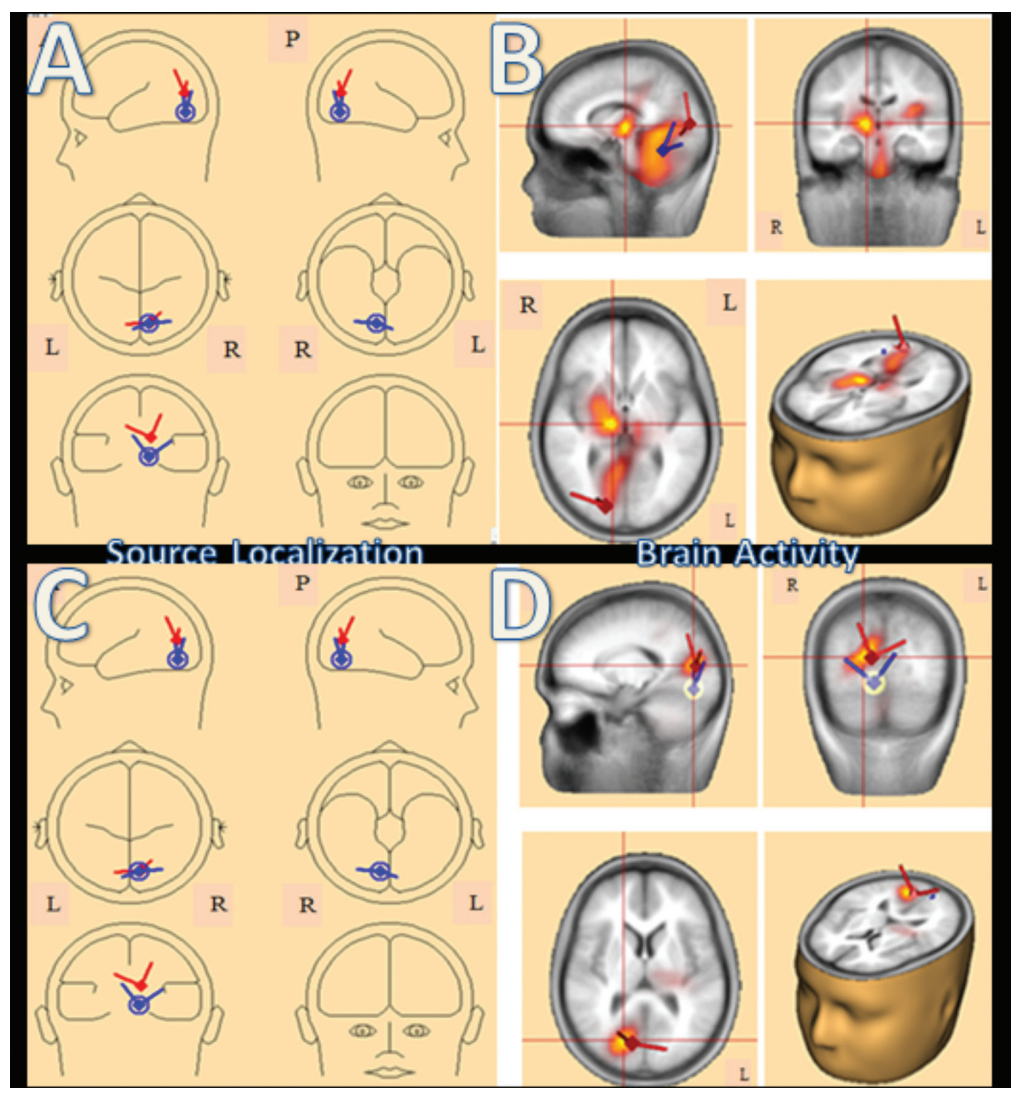

FIGURE 5. (A) Source localization and (B) brain activity of patient 1 during visual evoked field responses. The results indicated that unilateral activation in the visual areas. Brain activity and source localization are matched with stronger activation on the contralateral hemisphere to the tumour. The same pattern of the source localization (C) brain activity and

(D) is also shown in patient 2 but with reduce activation intensity in the right occipital. L: Left, R: Right, P: Posterior

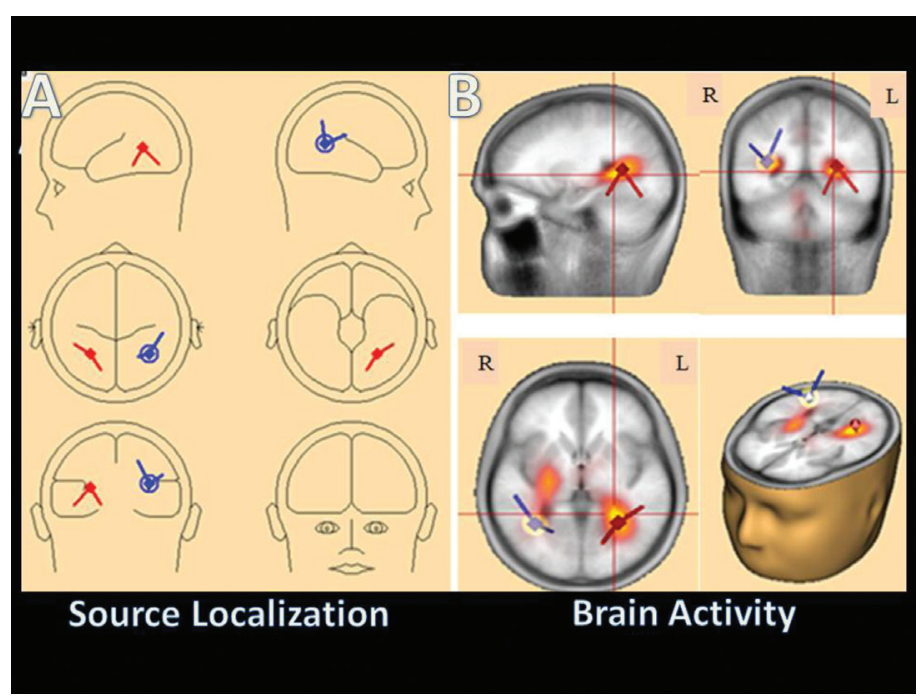

FIGURE 6. (A) Source localization and (B) brain activity of control participants were matched. The results showed activation of the bilateral occipital area during visual evoked fields. Brain activation of both hemispheres is recruited equally

activation shifts took place involving an early recruitment of contralesional homologous brain regions after a brain insult (Chen et al. 2010). Similar pattern of results was also found in stroke-induced aphasia suggesting an increased activation in the contralateral area of the lesion-language network, particularly in the right Broca-homologue during the subacute stage followed by re-shifting of main activation to left hemisphere language areas (Duffau 2005).

Our VEF-MEG result was also congruent with the diffusion tensor imaging (DTI) tractogram. DTI tractogram 
investigation showed extensive abnormalities, geometry and architecture of the optic tracts in the ipsilateral to the tumour (Figure 2(B)-2(C) and 3(B)-3(C)). The results also showed that there were no apparent optic tracts in the occipital area on the tumour side. The present result indicated that the ipsilateral white matter fibres optic tracts were also affected by the tumour. This abnormality is suggested to be due to the tumour invasion of the surrounding tissues, particularly the white matter tracts. This result was supported by the previous study that reported tumour such as LGG invades the main white-matter pathway within the lesional hemisphere and spread contralaterally via the corpus callosum (Walker \& Kaye 2003; Wang et al. 2009). This present study further suggested that LGG triggers a large functional reorganization within cerebral structures (Duffau 2014). Compared to the tumour side, the contralateral side demonstrates more appealing optic tracts. The present study suggested that the functional area of the hemisphere with lesion can be modified to the contralateral area. It is proposed that the mechanism of functional reorganization and neuroplasticity was taking place and possibly because of the existence of significant diffusion and redundant connectivity within the brain system, as well as the ability of the brain system to generate a new circuit to form through remapping (Chen et al. 2010).

\section{PATHOPHYSIOLOGICAL MECHANISMS} SUBSERVING NEUROPLASTICITY

In the present study, we proposed that the functional changes and optic tracts modification of VEF-MEG visual processing from bilateral area (normally in the usual normal participants) to unilateral activation and localization is one form of the mechanisms of the brain reorganization in response to the tumour growth involving the eloquent area. A pathophysiological mechanism underlying this reorganization is suggested that the functional-anatomy reorganization of the brain in human, both physiological and pathological has flexibility. The mechanisms of reorganization may differ according to the types and how fast the tumour grows, but with better functional compensation in more slowly growing tumour (Kunesch et al. 2003; Roux at al. 2000). For example in low grade glioma (LGG) such as PA, PA is the slowest growing brain tumour (Johnson et al. 2015). Recent studies has been reported that before any anaplastic transformation, PA shows a continuous, constant growth, with a mean tumour diameter growing on average $4 \mathrm{~mm}$ per year (Mandonnet et al. 2003). PA normally invade the main white-matter pathway within the hemisphere and spread contralaterally via corpus callosum (Giese et al. 2003). LGG frequently exhibit a complex configuration with a roughly ellipsoid shape, mimicking the subcortical pathways. The invaded brain tissue is often regarded as a homogeneous and passive region modified by the tumour in a unidirectional manner (Di et al. 2016). However, reciprocal processes and multiple sets of active and passive mechanisms are present in the invaded tissue. Furthermore, previous study has shown that the progressive LGG triggers a large functional reorganization and neuronal changes within the brain (Boadas-Vaello et al. 2106; Duffau 2006). Thus, this brain plasticity may allow a functional reorganization and rewiring to adapt to the environmental changes and therefore, initiate a functional compensation. Hence, it is not surprising that contralateral area to the tumour show higher brain activity and reduced activity in the ipsilateral (Duffau 2005). Interestingly, the patterns of reorganization may differ between patients. In the present study, due to the infiltrative feature of LGG, function has been shifted to the contralateral area of the tumour.

Brain tumour such as convexity meningioma also commonly are slow-growing tumours (Hu et al. 2009). Functional reorganization of these types of tumour is directly influenced by the kinetics of the lesion. Previous studies reported that the post-lesional recovery in acute lesions has been shown to involve mainly ipsilesional area adjacent to the injury (Behrman et al. 2006; BoadasVaello et al. 2016). The plastic potential of the brain system has been observed in the present study, with the different levels and type of brain tumour. Tumour induced a progressive redistribution of the eloquent sites in all patients, explaining why most of these patients have a slight deficit in neurological examination. The mechanism of neural plasticity is dependent on the modifications in its input environment, physiological changes and experiences. In the case of brain tumour, the mechanism of neuroplasticity is different to the normal plasticity. A consequence of neuroplasticity in the brain tumour is that specialised function can be shifted to different location (Chen et al. 2010); this might be due to the tumour suppressing the functioning processing of the particular area, therefore, other brain region will take over the processing centre. Furthermore, tumours can lead to reorganization of network responsible for visual processing (Duffau 2006; Rosler et al. 2014). Human brain plasticity or neuroplasticity, is the natural mechanism of the brain and nervous system, it is described as lasting change to the brain throughout life. This mechanism refers to the capacity of the system to reorganize their structure and function in response to the changes of the neuronal networks (Britton et al. 1994; Pascual-Leone et al. 2005).

\section{CONCLUSION}

Both neuropsychological and neuroimaging result of the three patients are consistent and demonstrate atypical result compared to control participants. This changes and alteration to the brain structural and function are due to the brain tumours that invade the functional areas of the brain. The present study suggests that the mechanisms of the tumour-induced plasticity are based on the intrinsic reorganisation within the lesion area. Consequently, this mechanism leads to the recruitment of other regions implicated in the original functional network, which is contralateral area to the tumour. 


\section{ACKNOWLEDGEMENTS}

The authors wish to thank Hazim Omar for data acquisition and Nur Amalina Hashim for neuropsychology assessment from Department of Neurosciences, Health Campus Universiti Sains Malaysia.

\section{REFERENCES}

Bashir, S., Mizrahi, I., Weaver, K., Fregni, F. \& Pascual-Leone, A. 2010. Assessment and modulation of neural plasticity in rehabilitation with transcranial magnetic stimulation. $P M \& R$ 2(12 Suppl 2): S253-S268.

Bavelier, D. \& Neville, H.J. 2002. Cross-modal plasticity: Where and how? Nature Reviews Neuroscience 3(6): 443-452.

Begley, S. \& Check, E. 2000. Rewiring your gray matter. The brain: You can teach an old brain new tricks. Neuroplasticity promises to give a whole new meaning to "changing your mind'. Newsweek 134(26): 63-65.

Behrman,A.L., Bowden, M.G. \& Nair, P.M. 2006. Neuroplasticity after spinal cord injury and training: An emerging paradigm shift in rehabilitation and walking recovery. Physical Therapy 86(10): 1406-1425.

Boadas-Vaello, P., Castany, S., Homs, J., Alvarez-Perez, B., Deulofeu, M. \& Verdu, E. 2016. Neuroplasticity of ascending and descending pathways after somatosensory system injury: Reviewing knowledge to identify neuropathic pain therapeutic targets. Spinal Cord 54(5): 330-340.

Boissonneau, S. \& Duffau, H. 2017. Identifying clinical risk in low grade gliomas and appropriate treatment strategies, with special emphasis on the role of surgery. Expert Review of Anticancer Therapy 17(8): 703-716.

Britton, J.W., Cascino, G.D., Sharbrough, F.W. \& Kelly, P.J. 1994. Low-grade glial neoplasms and intractable partial epilepsy: Efficacy of surgical treatment. Epilepsia 35(6): 1130-1135.

Chen, H., Epstein, J. \& Stern, E. 2010. Neural plasticity after acquired brain injury: Evidence from functional neuroimaging. $P M \& R 2$ (12 Suppl 2): S306-S312.

Dellani, P.R., Glaser, M., Wille, P.R., Vucurevic, G., Stadie, A., Bauermann, T., Tropine, A., Perneczky, A., von Wangenheim, A. \& Stoeter, P. 2007. White matter fiber tracking computation based on diffusion tensor imaging for clinical applications. Journal of Digital Imaging 20(1): 88-97.

Di, J., Cohen, L.S., Corbo, C.P., Phillips, G.R., El Idrissi, A. \& Alonso, A.D. 2016. Abnormal tau induces cognitive impairment through two different mechanisms: Synaptic dysfunction and neuronal loss. Scientific Reports 6: 20833.

Duffau, H. 2014. Diffuse low-grade gliomas and neuroplasticity. Diagnostic and Interventional Imaging 95(10): 945-55.

Duffau, H. 2006. Lessons from brain mapping in surgery for lowgrade gliomas: Study of cerebral connectivity and plasticity. Medical Imaging and Augmented Reality 4091: 25-35.

Duffau, H. 2005. Lessons from brain mapping in surgery for low-grade glioma: Insights into associations between tumour and brain plasticity. The Lancet Neurology 4(8): 476-486.

Giese, A., Bjerkvig, R., Berens, M.E. \& Westphal, M. 2003. Cost of migration: Invasion of malignant gliomas and implications for treatment. Journal of Clinical Oncology 21(8): 1624-1636.

Hu, W., Shen, F., Chen, G., Shen, G., Liu, W. \& Zhou, J. 2009. Possible involvement of brain tumour stem cells in the emergence of a fast-growing malignant meningioma after surgical resection and radiotherapy of high-grade astrocytoma: Case report and preliminary laboratory investigation. Journal of International Medical Research 37(1): 240-246.

Johnson, P., Jaggon, J.R., Campbell, J., Bruce, C., Ferron, D., James, K., Crandon, I. \& Eldemire-Shearer, D. 2015. Profile of a malignant brain tumour in Jamaica: An eight-year review, 2005 to 2012. West Indian Medical Journal 64(4): 372-375.

Krieg, S.M., Sollmann, N., Hauck, T., Ille, S., Foerschler, A., Meyer, B. \& Ringel, F. 2013. Functional language shift to the right hemisphere in patients with language-eloquent brain tumors. PLoS One 8(9): e75403.

Kunesch, E., Classen, J., Bettag, M., Kahn, T., Ulrich, F., Bock, W.J., Freund, H.J. \& Seitz, R.J. 2003. Representational cortical plasticity associated with brain tumours: Evidence from laser-induced interstitial thermotherapy. Acta Neurologica Scandinavica 108(3): 201-208.

Maeshima, S., Shigeno, K., Dohi, N., Kajiwara, T. \& Komai, N. 1992. A study of right unilateral spatial neglect in left hemispheric lesions: The difference between right-handed and non-right-handed post-stroke patients. Acta Neurologica Scandinavica 85(6): 418-424.

Manan, H.A., Franz, E.A., Yusoff, A.N. \& Mukari, S.Z. 2015 The effects of aging on the brain activation pattern during a speech perception task: An fMRI study. Aging Clinical and Experimental Research 27(1): 27-36.

Mandonnet, E., Delattre, J.Y., Tanguy, M.L., Swanson, K.R., Carpentier, A.F., Duffau, H., Cornu, P., van Effenterre, R., Alvord,E.C. \& Capelle,L. 2003. Continuous growth of mean tumor diameter in a subset of grade II gliomas. Annals of Neurology 53(4): 524-528.

Mizuno, K., Tsuji, T., Rossetti, Y., Pisella, L., Ohde, H. \& Liu, M. 2013. Early visual processing is affected by clinical subtype in patients with unilateral spatial neglect: A magnetoencephalography study. Frontiers in Human Neuroscience 7: 432.

Mori, S. \& van Zijl, P.C. 2002. Fiber tracking: Principles and strategies - a technical review. NMR in Biomedicine 15(78): 468-480.

Nakamura, M., Yanagisawa, T., Okamura, Y., Fukuma, R., Hirata, M., Araki, T., Kamitani, Y. \& Yorifuji, S. 2015. Categorical discrimination of human body parts by magnetoencephalography. Frontiers in Human Neuroscience 9: 609 .

Oberlin, L.E., Verstynen, T.D., Burzynska, A.Z., Voss, M.W., Prakash, R.S., Chaddock-Heyman, L., Wong, C., Fanning, J., Awick, E., Gothe, N., Phillips, S.M., Mailey, E., Ehlers, D., Olson, E., Wojcicki, T., McAuley, E., Kramer, A.F. \& Erickson, K.I. 2015. White matter microstructure mediates the relationship between cardiorespiratory fitness and spatial working memory in older adults. NeuroImage 131: 91-101.

Park, Y., Yu, E.S., Ha, B., Park, H.J., Kim, J.H. \& Kim, J.Y. 2017. Neurocognitive and psychological functioning of children with an intracranial germ cell tumor. Cancer Research and Treatment 49(4): 960-969.

Pascual-Leone, A., Amedi, A., Fregni, F. \& Merabet, L.B. 2005. The plastic human brain cortex. Annual Review of Neuroscience 28: 377-401.

Reichert, J.L., Chocholous, M., Leiss, U., Pletschko, T., Kasprian, G., Furtner, J., Kollndorfer, K., Krajnik, J., Slavc, I., Prayer, D., Czech, T., Schopf, V. \& Dorfer, C. 2017. Neuronal correlates of cognitive function in patients with childhood cerebellar tumor lesions. PLoS One 12(7): e0180200.

Rosler, J., Niraula, B., Strack, V., Zdunczyk, A., Schilt, S., Savolainen, P., Lioumis, P., Makela, J., Vajkoczy, P., 
Frey, D. \& Picht, T. 2014. Language mapping in healthy volunteers and brain tumor patients with a novel navigated TMS system: Evidence of tumor-induced plasticity. Clinical Neurophysiology 125(3): 526-536.

Roux, F.E., Boulanouar, K., Ibarrola, D., Tremoulet, M., Chollet, F. \& Berry, I. 2000. Functional MRI and intraoperative brain mapping to evaluate brain plasticity in patients with brain tumours and hemiparesis. Journal of Neurology, Neurosurgery, and Psychiatry 69(4): 453-463.

Sabbah, N., Sanda, N., Authie, C.N., Mohand-Said, S., Sahel, J.A., Habas, C.,Amedi,A.\& Safran,A.B. 2017. Reorganization of early visual cortex functional connectivity following selective peripheral and central visual loss. Scientific Reports 7: 43223.

Seki, Y., Kandori, A., Ogata, K., Miyashita, T., Kumagai, Y., Ohnuma, M., Konaka, K. \& Naritomi, H. 2010. Note: Unshielded bilateral magnetoencephalography system using two-dimensional gradiometers. Review of Scientific Instruments 81(9): 096103.

Shahani, U., Lang, G., Mansfield, D.C., Halliday, D.M., Weir, A.I., Maas, P. \& Donaldson, G.B. 2001. Magnetoencephalography and stereopsis: Rhythmic cortical activity in humans recorded over the parieto-occipital cortex. Neuroscience Letters 315(3): 154-158.

Walker, D.G. \& Kaye, A.H. 2003. Low grade glial neoplasms. Journal of Clinical Neuroscience 10(1): 1-13.

Wang, W., Steward, C.E. \& Desmond, P.M. 2009. Diffusion tensor imaging in glioblastoma multiforme and brain metastases: The role of p, q, L, and fractional anisotropy. American Journal of Neuroradiology 30(1): 203-208.

Wilkinson, D., Ko, P., Wiriadjaja, A., Kilduff, P., McGlinchey, R. \& Milberg, W. 2009. Unilateral damage to the right cerebral hemisphere disrupts the apprehension of whole faces and their component parts. Neuropsychologia 47(7): 1701-1711.
Hanani Abdul Manan*

Department of Radiology

Pusat Perubatan Universiti Kebangsaan Malaysia

Jalan Yaacob Latif, Bandar Tun Razak

56000 Cheras, Kuala Lumpur, Federal Territory

Malaysia

Zamzuri Idris \& Jafri Malin Abdullah

Center for Neuroscience Service and Research

School of Medical Sciences

Universiti Sains Malaysia

16150 Kubang Kerian, Kelantan Darul Naim

Malaysia

Zamzuri Idris, Mohammed Faruque Reza,

Wan Nor Azlen Wan Mohamad \& Jafri Malin Abdullah

Department of Neurosciences

School of Medical Sciences

Universiti Sains Malaysia

16150 Kubang Kerian, Kelantan Darul Naim

Malaysia

*Corresponding author; email: hanani@ukm.edu.my

Received: 3 January 2017

Accepted: 29 September 2017 